\title{
A Randomized Telephone Intervention Trial to Reduce Primary Medication Nonadherence
}

\author{
Michael A. Fischer, MD, MS; J.B. Jones, PhD, MBA; Eric Wright, PharmD, BCPS; Ryan P. Van Loan; \\ Jing Xie, MD, ScD; Lauren Gallagher, MPH; Aaron M. Wurst; and William H. Shrank, MD, MSHS
}

\section{ABSTRACT}

BACKGROUND: Primary medication nonadherence (PMN), defined as patients not picking up an initial prescription, can limit the effectiveness of therapy for chronic conditions. Effective interventions to reduce PMN have not been widely studied or implemented.

OBJECTIVE: To evaluate the ability of an additional nurse-directed telephone intervention to reduce PMN in a cohort of patients with persistent nonadherence after repeated pharmacy-based outreach.

METHODS: Patients in the Geisinger Health System receiving new (i.e., initially prescribed) prescriptions sent to CVS pharmacies for medications treating asthma, hypertension, diabetes, or hyperlipidemia were identified. As part of existing programs, all patients received 2 automated and 1 live call from CVS pharmacies encouraging them to pick up their prescriptions; those who had canceled their prescriptions or had not picked them up after the 3 pharmacy interventions were eligible for this study. Patients were then randomized, and the intervention group received telephone outreach from a nursing call center to assess reasons for PMN and encourage pickup of prescriptions, with up to 3 attempts to reach each patient. Medication pickup rates were compared across the intervention and control groups. RESULTS: Initial PMN rates in the overall population were $6 \%$, lower than previously observed in other studies. A total of 290 patients had not picked up their prescriptions after 3 calls from the pharmacy and were enrolled in the study: 142 in the intervention group and 148 controls. The intervention did not change the rate at which patients picked up their prescriptions: $25 \%$ of intervention patients did so compared with $24 \%$ of control patients. Multivariate models adjusting for patient characteristics and medication classes did not change the results.

CONCLUSIONS: In a population of patients who had not picked up new prescriptions after 3 calls from the pharmacy, additional nurse-directed outreach did not improve primary medication adherence. Re-engagement with the prescribing clinician may be needed to improve adherence in this patient population. The low rate of PMN in the overall population differed from prior studies in this setting and others and should be assessed in future research.

J Manag Care Pharm. 2015;21(2):124-31

Copyright $\odot 2015$, Academy of Managed Care Pharmacy. All rights reserved.

\section{What is already known about this subject}

Primary medication nonadherence (PMN) occurs for 15\%-30\% of prescriptions, so that many patients never start taking medications prescribed to treat chronic diseases.

Multiple factors contribute to PMN, making it difficult to address. Patients in integrated health care systems usually have lower rates of PMN, although many still do not pick up new prescriptions.

\section{What this study adds}

A telephonic intervention from the physician's office targeting patients who had not picked up new prescriptions after 3 phone calls from the pharmacy did not reduce PMN any further.

Increasing medication adherence among patients who do not pick up prescriptions promptly may be difficult to accomplish; timely interventions should be developed and implemented.

Implementing new interventions to address PMN can face multiple practical and logistical challenges.

The rate of PMN may be decreasing relative to the findings of earlier studies.

$\mathrm{N}$ onadherence to essential chronic medications is a central public health problem, leading to substantial morbidity, mortality, and avoidable health care costs that are estimated at $\$ 100$ billion a year or more in the United States. ${ }^{1-3}$ Extensive evaluation of the rates $^{4-6}$ and predictors ${ }^{7-12}$ of nonadherence have been conducted, and numerous interventions have been implemented to improve the way patients take their medications. ${ }^{13-15}$ However, an important component of taking medication has been largely overlooked until the past several years. Previous studies required patients to have already picked up an initial prescription for a medication and then evaluated subsequent refills. Little data were available to accurately assess how often patients receive a written prescription but fail to pick it up-known as primary medication nonadherence (PMN).

With the advent of electronic prescribing, precise information about prescriptions written but not picked up became available. A recent study of over 195,000 electronically written prescriptions in community practice found that $22 \%$ were never picked up by patients. Among newly prescribed medications, 28\% of prescriptions were never picked up, ${ }^{16}$ which was later confirmed in a subsequent analysis on a much larger population. ${ }^{17}$ Investigators have also found important patient and prescription-level characteristics associated with failure to pick up a prescription once bottled, including decreasing PMN with increasing age and with the presence of a pharmacy drug benefit. ${ }^{18}$ Studies in integrated health care systems have found lower rates of PMN (15\%-17\% for antihypertensives and antidiabetic medications), but the scope of the problem is substantial even in these settings. ${ }^{19-24}$ 
Although PMN has been documented as a problem that might limit the effectiveness of care, few interventions to address PMN have been developed or evaluated. We implemented and evaluated an intervention that used pharmacy data to identify PMN and telephonic outreach from nurses affiliated with the patient's primary care provider to encourage adherence to newly prescribed medications.

\section{Methods}

\section{Study Design and Setting}

We conducted a prospective randomized controlled trial of a telephonic intervention to reduce PMN. We focused on medications prescribed for the following common chronic conditions: hypertension, hyperlipidemia, asthma, and type 2 diabetes. The prescribed medications included multiple routes of delivery: oral, inhaled, and injectable. The intervention occurred within the family practice and internal medicine departments of Geisinger Health System. Geisinger Health System is an integrated health care delivery network serving patients in central and northeastern Pennsylvania. The Geisinger Health System includes the Geisinger Clinic, a network of over 40 community-based clinics staffed by primary care physicians. The Geisinger Clinic network provides primary care to over 400,000 patients. All clinic locations have used the EpicCare electronic health record (EHR) since 2001. A total of 24 clinics were included. The Geisinger Health System Institutional Review Board approved this study.

\section{Clinic and Patient Selection}

The study design relied on identifying PMN using order data from the Geisinger EHR and pharmacy data provided by CVS. Clinics were selected based on volume of electronic prescriptions transmitted to CVS pharmacies. In the Geisinger EHR, each time a provider places an order for a medication, the patient is asked to confirm a chosen pharmacy. If the pharmacy has electronic prescribing (e-prescribing) capabilities, the order is sent electronically to the patient's chosen pharmacy. If the patient's pharmacy of choice does not have e-prescribing capabilities, a paper prescription is printed and given to the patient. To select clinic sites, we reviewed e-prescribing activity in the prior 12 months and identified the clinics with the highest volume of e-prescriptions for an included medication and which were sent to a CVS pharmacy location. Based on this analysis of e-prescribing volume and with feedback from Geisinger Clinic leadership, we identified 24 clinics that would allow us to reach our desired sample size during the study period.

Patients were eligible for inclusion if they met the following criteria: (a) had a Geisinger primary care physician; (b) received a new order for an antihypertensive, antidiabetic, antiasthmatic, or antihyperlipidemic medication; and (c) selected a CVS pharmacy as the destination for the e-prescription associated with the new medication. Medications were considered new if the patient had no prior record of an order for the inclusion medication or any medication in the same subclass (e.g., beta-blocker) prescribed within the previous year. Patients were eligible for inclusion for only 1 medication and only once during the study period.

\section{Study Enrollment}

Patients were automatically enrolled in the study at the time their providers placed an order in the EHR for 1 of the included medications. Upon ordering an eligible medication, the EHR was programmed to trigger a Best Practice Alert (BPA). The BPA asked the provider to respond to the following question: "In your opinion, how likely is it that this patient will pick up this medication?" The provider could select from a 5-point Likert scale with options ranging from "very unlikely" to "very likely." The BPA could also be closed or ignored without responding to the question.

Medication orders for patients who met inclusion criteria for the provider question were electronically sent to the chosen CVS pharmacy. CVS pharmacies processed prescription orders for these patients following their standard operating procedure, which includes automated voice phone call reminders at day 3 and 7, and a live pharmacist call between days 10-14 for any patients who had not picked up their medications at the time a reminder call was scheduled to occur. Any medications not picked up within 14 days after the medication order were returned to stock (RTS). Prescriptions that were canceled by the patients were also RTS. Following RTS, the medication is still available to the patient, but it is no longer stored in a medication pickup bin.

\section{Intervention}

The intervention was designed to test whether patients who exhibited PMN were more likely to pick up their medications when contacted by a member of their primary care team after repeated efforts from the pharmacy were unsuccessful. Patients were randomized when their prescriptions were canceled or RTS. For the first 2 months of the study period, only patients who had prescriptions RTS after 14 days were enrolled. When it became clear that some of the PMN was occurring due to patients canceling their prescriptions, then these patients were added to the randomized population. Those patients identified as primary medication nonadherent by this method were then randomized into 1 of 2 groups: nurse-call intervention or usual care on a 1:1 basis.

The intervention consisted of a telephone call placed by nurses working with the provider who prescribed the eligible medication. Nurses on the "Care Gaps" team routinely contact patients to support Geisinger quality initiatives, such as scheduling routine mammography screenings, preparing patients for their diabetic exams, and other similar outreach programs. Over the course of 2 or more days, up to 3 attempts to reach the 


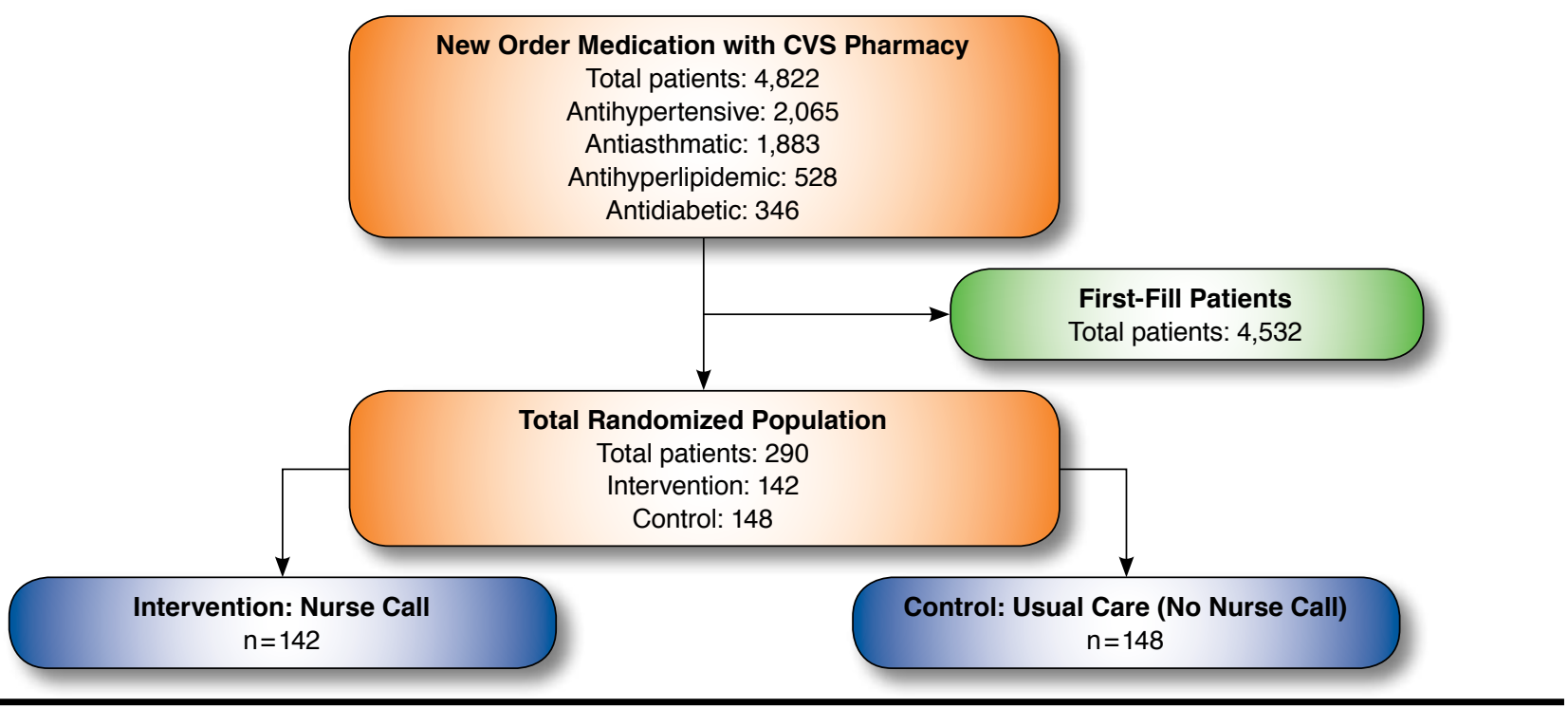

patient at different times of the day were made by the nurses. A generic reminder message was left on an answering machine if the patient or caregiver was not reached. Nurses who reached a patient or caregiver for the patient reminded him or her that the prescription was available to be picked up at the pharmacy and documented the following information in a telephone encounter in the EHR: date and time of the call, call disposition (e.g., patient reached, wrong number), if the patient reported picking up the medication, date and location of where medication was picked up, and any reasons the patient provided, unprompted, on why medication was not picked up.

\section{Outcomes}

The primary outcome was patient pickup of a prescription within 30 days after the initial order. Patient medication pickup was identified in CVS pharmacy records, so prescriptions filled at other pharmacies were not captured.

\section{Sample Size}

We aimed to detect a $12.5 \%$ difference in pickup rates between intervention and control groups, assuming that among patients who had not picked up their prescriptions within 14 days the control group rate of subsequent pickup would be only $10 \%$. Using a 2-sided Fisher's exact test for proportions, we required 149 patients per group to detect a proportional difference of 0.125 with $80 \%$ power with a significance level of 0.05 .

\section{Statistical Analysis}

The primary outcome of interest was pickup of the index prescription within 30 days. A patient was considered as having picked up if the prescription was claimed within 30 days of the EHR order. ${ }^{25}$ Univariate analysis was conducted to examine the difference in pickup rate between intervention and control groups. T-tests or Wilcoxon rank sum tests were used for continuous variables. Chi-square tests were used for categorical variables. We developed a multivariate logistic regression model to estimate odds ratios (OR) and 95\% confidence intervals (CI) of filling prescriptions, comparing the intervention group with the control group. Covariates were selected based on scientific plausibility and backward selection $(P<0.10)$, including age (continuous); index drug class (asthma, diabetes, hypertension, and lipids); Charlson score (continuous); and insurance status (commercial vs. others) - all assessed at the time of the index prescription order. The model convergence criterion was satisfied. Due to the limited sample size, we did not perform any assessment for variable interaction or collinearity. We used SAS 9.2 software (SAS Institute, Cary, NC) for all analyses and used 2 -sided $P$ values.

\section{Results}

Figure 1 shows the flow of patient enrollment in the study. Unexpectedly, 94\% of patients picked up their index prescription before becoming eligible for the study $(4,532 / 4,822)$, a much lower rate of PMN than found in prior observational studies either in the Geisinger system or elsewhere..$^{20,21}$ The low rate of PMN resulted in much slower than anticipated addition of patients to the study population, with final total enrollment of 290 patients rather than the prespecified target of 298. Table 1 shows the characteristics of the 4,532 patients who picked up 
TABLE 1 Patient Characteristics: All Eligible Patients Versus Those Enrolled

\begin{tabular}{|c|c|c|c|c|c|}
\hline \multirow[b]{2}{*}{ Characteristic } & \multicolumn{2}{|c|}{ Randomized (N = 290) } & \multicolumn{2}{|c|}{ Adherent $(\mathrm{N}=4,532)$} & \multirow[b]{2}{*}{$P$ Value } \\
\hline & $\mathrm{N}$ or Mean & SD or $\%$ & $\mathrm{~N}$ or Mean & SD or $\%$ & \\
\hline Age at index Rx (years), mean & 48.4 & 17.4 & 53.5 & 16.5 & $<0.0001$ \\
\hline White & 273 & 94.1 & 4,370 & 96.4 & 0.05 \\
\hline Female & 167 & 57.6 & 2,497 & 55.1 & 0.57 \\
\hline Index drug category & & & & & $<0.001$ \\
\hline Asthma & 165 & 56.9 & 1,718 & 37.9 & $<0.0001$ \\
\hline Diabetes & 22 & 7.6 & 324 & 7.2 & 0.77 \\
\hline Hypertension & 69 & 23.8 & 1,996 & 44.0 & $<0.001$ \\
\hline Lipids & 34 & 11.7 & 494 & 10.9 & 0.56 \\
\hline Patients with the index drug dispensed in the prior 13 months & 19 & 6.6 & 99 & 2.2 & $<0.0001$ \\
\hline Medical condition/disease & & & & & $<0.001$ \\
\hline Asthma & 99 & 22.9 & 965 & 12.8 & $<0.0001$ \\
\hline Diabetes & 63 & 14.6 & 1,146 & 15.3 & 0.50 \\
\hline Dyslipidemia & 141 & 32.6 & 2,670 & 35.5 & 0.0013 \\
\hline Hypertension & 130 & 30.0 & 2,732 & 36.4 & $<0.001$ \\
\hline Charlson score & 1.03 & 1.01 & 1.06 & 1.37 & 0.73 \\
\hline Drug benefit/insurance & & & & & $<0.001$ \\
\hline Commercial & 219 & 75.8 & 3,567 & 78.7 & $<0.0001$ \\
\hline Medicaid & 13 & 4.5 & 87 & 1.9 & 0.06 \\
\hline Medicare & 38 & 13.2 & 762 & 16.8 & 0.01 \\
\hline Self-pay & 19 & 6.6 & 116 & 2.6 & 0.004 \\
\hline
\end{tabular}

TABLE 2 Randomized Patient Characteristics: Control Group Versus Intervention Group

\begin{tabular}{|c|c|c|c|c|c|}
\hline Characteristic & $\mathrm{N}$ or Mean & SD or $\%$ & $\mathrm{~N}$ or Mean & SD or $\%$ & $P$ Value \\
\hline Age at index Rx (years), mean & 46.7 & 17.5 & 50.3 & 17.3 & 0.08 \\
\hline White & 136 & 91.9 & 137 & 96.5 & 0.10 \\
\hline Female & 88 & 59.5 & 79 & 55.6 & 0.51 \\
\hline Index drug category & & & & & 0.20 \\
\hline Asthma & 89 & 60.1 & 76 & 53.5 & 0.09 \\
\hline Diabetes & 7 & 4.7 & 15 & 10.6 & 0.37 \\
\hline Hypertension & 37 & 25.0 & 32 & 22.5 & 0.62 \\
\hline Lipids & 15 & 10.1 & 19 & 13.4 & 0.57 \\
\hline Patients with the index drug dispensed in the prior 13 months & 9 & 6.1 & 10 & 7.0 & 0.74 \\
\hline Medical condition/disease & & & & & 0.06 \\
\hline Asthma & 56 & 26.9 & 43 & 19.1 & 0.05 \\
\hline Diabetes & 22 & 10.6 & 41 & 18.2 & 0.12 \\
\hline Dyslipidemia & 66 & 31.7 & 75 & 33.3 & 0.69 \\
\hline Hypertension & 64 & 30.8 & 66 & 29.3 & 0.35 \\
\hline Charlson score & 0.97 & 0.92 & 1.08 & 1.09 & 0.35 \\
\hline Drug benefit/insurance & & & & & 0.22 \\
\hline Commercial & 105 & 71.0 & 114 & 80.9 & 0.002 \\
\hline Medicaid & 9 & 6.1 & 4 & 2.8 & 0.47 \\
\hline Medicare & 22 & 14.9 & 16 & 11.4 & 0.50 \\
\hline Self-pay & 12 & 8.1 & 7 & 5.0 & 0.54 \\
\hline
\end{tabular}

their prescriptions promptly compared with the 290 enrolled in the study. The patients enrolled in the study were younger, more likely to have asthma, less likely to have hypertension, and more likely to have Medicaid or be self-paying for their care. The 290 nonadherent patients who met study inclusion criteria were randomized into an intervention group $(n=142)$ 
TABLE 3 Distribution of Patient Responses Among 50 Patients Who Were Reached

\begin{tabular}{|c|c|c|c|}
\hline Patient Response & Frequency & Percentage & Filled Later \\
\hline Patient already picked up prescription & 9 & 18 & 5 \\
\hline Patient will pick up prescription & 8 & 16 & 1 \\
\hline Prescription not picked up; patient understandinga & 7 & 14 & 2 \\
\hline Prescription not picked up; no insurance/high copay/cannot afford medication & 10 & 20 & 3 \\
\hline Prescription not picked up; patient forgot & 2 & 4 & 1 \\
\hline Prescription not picked up; patient switched to different medication; or patient canceled medication & 6 & 12 & 2 \\
\hline Prescription not picked up; other & 8 & 16 & 1 \\
\hline
\end{tabular}

ancludes prior bad experience with medications; patient does not understand why medication was prescribed; or patient doubts need for medication.

TABLE 4 Prescription Filling Rates Intervention Versus Control Groups

\begin{tabular}{|c|c|c|c|c|c|c|c|}
\hline \multirow[b]{2}{*}{ Drug Class } & \multicolumn{3}{|c|}{$\begin{array}{l}\text { Control Group } \\
(\mathrm{N}=148)\end{array}$} & \multicolumn{3}{|c|}{$\begin{array}{l}\text { Intervention Group } \\
\qquad(\mathrm{N}=142)\end{array}$} & \multirow[b]{2}{*}{$\begin{array}{c}P \\
\text { Value }\end{array}$} \\
\hline & $\begin{array}{c}\text { Total } \\
\text { Rx }\end{array}$ & $\begin{array}{l}\text { Filled } \\
(\mathrm{n})\end{array}$ & $\%$ & $\begin{array}{c}\text { Total } \\
\text { Rx }\end{array}$ & $\begin{array}{l}\text { Filled } \\
(\mathbf{n})\end{array}$ & $\%$ & \\
\hline All classes & 148 & 35 & 23.6 & 142 & 36 & 25.4 & 0.74 \\
\hline Asthma & 89 & 18 & 20.2 & 76 & 17 & 22.4 & 0.74 \\
\hline Diabetes & 7 & 2 & 28.6 & 15 & 3 & 20.0 & 1.00 \\
\hline Hypertension & 37 & 10 & 27.3 & 32 & 15 & 46.9 & 0.09 \\
\hline Lipids & 15 & 5 & 33.3 & 19 & 1 & 5.3 & 0.03 \\
\hline
\end{tabular}

aP values from chi-square test.

Rx= prescription

and a control group $(n=148)$. Table 2 shows that major characteristics were balanced across the 2 groups.

Implementation of the intervention revealed important challenges in patient outreach. Due to a database error, 13 of the 142 patients randomized to receive the intervention were not called during the intervention period, although they were included in the intention-to-treat analyses. Of the 129 patients who were called, 50 (39\%) spoke in person with the outreach nurses; messages were left for the remaining 79 patients, but it could not be confirmed that the patients received the messages. Table 3 shows the responses of the patients with whom the nurses spoke; 15 (30\%) of those patients ended up picking up their medications. Although 17 of the patients who spoke with the nurses reported that they already had or would pick up their prescriptions, only 6 of those 17 patients actually picked up their prescriptions at a CVS pharmacy. Reasons for not picking up prescriptions included problems with medication costs, poor understanding of the reason for the prescription, or prior problems with medications.

Table 4 shows the proportion of patients in the intervention and control groups who picked up their index prescriptions. Among intervention patients, 25\% returned to pick up their prescriptions, with a rate of $24 \%$ in control patients. Table 4 also shows rates of prescription pickup across different medication subclasses-pickup of anithypertensive medications in
TABLE 5 Multivariate-Adjusted Odds Ratios (95\% Cl) of Filling Rate

\begin{tabular}{l|c|c|c}
\hline Variables & Odds Ratio & $95 \%$ CI & $P$ Value \\
\hline Intervention vs. control & 1.08 & $0.62-1.89$ & 0.79 \\
\hline Age & 1.02 & $1.00-1.04$ & 0.06 \\
\hline \multicolumn{3}{|l}{ Index drug class } & \\
\hline Asthma (reference) & 1.00 & & \\
\hline Diabetes & 0.95 & $0.32-2.87$ & 0.93 \\
\hline Hypertension & 1.78 & $0.94-3.39$ & 0.08 \\
\hline Lipids & 0.66 & $0.25-1.76$ & 0.41 \\
\hline Charlson score & 0.91 & $0.68-1.22$ & 0.53 \\
\hline Commercial insurance & 0.95 & $0.50-1.80$ & 0.86 \\
\hline
\end{tabular}

aP values from multivariate logistic regression models.

CI= confidence interval.

the intervention group was the subset with the highest adherence (47\%). Results from the multivariate-adjusted logistic regression model (Table 5) showed that intervention patients were no more likely to have picked up their medications within 30 days ( $\mathrm{OR}=1.08,95 \% \mathrm{CI}=0.62-1.89, P=0.79)$. Model results showed a trend towards increased prescription pickup with increasing age $(\mathrm{OR}=1.02$ for each additional year, 95\% $\mathrm{CI}=1.00-1.04, P=0.06)$. There was also a trend to increased pickup of antihypertensive medications compared with asthma medications $(\mathrm{OR}=1.78,95 \% \mathrm{CI}=0.94-3.39, \mathrm{P}=0.08)$. No significant difference in the pickup rates was observed for other medication classes, Charlson score, or insurance status.

After the study was completed and while data were being analyzed, we identified an error in the EHR algorithm that identified prior use of the index medication class. A total of 113 patients in the overall population $(113 / 4,822,2 \%)$ had previously received their index medications, including 19 (7\%) of the 290 patients in the randomized populations. An additional 29 patients received medications from the same therapeutic subclass as the index medications. All analyses were repeated excluding patients who had previously received the index medications or medications from the same therapeutic subclass, and the results did not differ from the initial analyses (Appendices A-E, available in online article). 


\section{Discussion}

We evaluated a primary care practice-based intervention aimed at reducing the rate of PMN. The most striking finding in this study was the extremely low rate of PMN-only $6 \%$ of patients prescribed a new medication did not pick it up within 14 days. Among the patients who were enrolled in the study, medication adherence was very low and was not significantly changed by the telephonic intervention.

The low rate of PMN among the patients screened for this study differs from the previous literature. Two studies of large populations of patients in different clinical settings found PMN rates over $20 \%,{ }^{16,17}$ and studies of PMN for patients in the Geisinger system found PMN rates of 15\%-17\% among patients prescribed antihypertensive and oral diabetes medications. ${ }^{20,21}$ Our considerably lower PMN rates are similar to those seen in recent reports from other integrated health care settings, ${ }^{22-24}$ suggesting perhaps the structure of the health system or the use of e-prescribing was a factor in first-fill rates. However, a key difference between these studies and ours is the use of primarily in-network pharmacies versus our use of an independent pharmacy chain. This is an important distinction, since obtaining medication from the in-network pharmacy location requires very little to no effort on the part of the patient and may therefore result in very low PMN rates-whether this impacts subsequent filling behavior is unknown. Our study found similarly low PMN rates despite the need for patients to obtain the medication at an external community pharmacy. A follow-up study of second fill rates among our patients would provide insight into the early persistence of our patients compared with those in other integrated health systems.

One possible explanation for the low PMN in this population is the use of an alert in the EHR asking physicians how likely they thought the patient was to fill the medication. The presence of this question may create a Hawthorne effect, either causing prescribers to push harder for adherence or causing them to cancel prescriptions for which they thought adherence was unlikely. The data that we obtained for this study cannot assess that possibility, but future work on whether providerdirected questions such as the one described here have an impact on PMN would be important. A simpler explanation would be that PMN is improving over time, that is, more patients are picking up new prescriptions now than in the past. More consistent use of e-prescriptions and use of only 1 pharmacy chain with a pre-existing pharmacy fill outreach program also present mechanisms for this unexpectedly high first-fill rate.

In addition to the low baseline rate of PMN, the impact of the intervention itself was very limited and did not approach statistical significance. The patients who were enrolled in the study had either cancelled an initial prescription or who had already received multiple telephonic interventions from CVS yet had not picked up the new prescriptions. It may be that most of the patients identified for randomization had decided not to take the medications prescribed. In this scenario, an incremental reminder intervention after multiple prior attempts may be less likely to change adherence decisions, and more detailed reengagement with the prescribing physician may be required. The study most similar to this was recently performed in the Kaiser system by DeRose et al. (2013) and did find a reduction in PMN with use of an automated telephone call and followup letter, although without the initial calls that preceded our intervention. ${ }^{19}$ Of note, the PMN rate in the DeRose study was much higher than the rate observed in this study, which left potential for improvement that may not have been present for our intervention given the very low baseline PMN.

The effectiveness of the intervention may also have been attenuated by the delayed and limited role that the Care Gaps nurses had in the intervention. Despite the reminder call, the study nurses reached less than half of the patients assigned, and of those reached, the intervention was limited to a reminder versus a more thorough discussion. Lower touch reminders using interactive voice messaging or live persons may have some effectiveness when they occur in close proximity to the prescription, but we found that they were ineffective when applied to patients who had already declined to pick up following the pharmacy's own outreach effort. These patients may be better candidates for a more intensive intervention, including telephonic motivational interviewing or face-to-face consultation.

Several challenges arose in the implementation of the intervention, including enrollment of patients who had previously used the index medications, patients not appearing on nurse call lists, and difficulties in reaching patients on the phone. It is important to note that this study was performed in a wellintegrated health system-in most other settings, the logistical challenges would be even larger. Future attempts to implement similar interventions will need to consider the complexity of most systems of care and the difficulty of outreach to patients.

\section{Limitations}

This study has important limitations that must be kept in mind when interpreting the results. Several technical and practical challenges in implementing the intervention may have limited the potential impact. Specifically, although our original study design included a question for prescribers about their estimation of the likelihood that the patient would fill the prescription, consideration of the needs of physician workflow forced us to make this question optional, which prevented it from being part of the analyses. Similarly, the calls to patients from nurses did not include systematic assessments of the reasons that some prescriptions were canceled at the pharmacy, 
limiting our ability to understand the causes of persistent nonadherence. That these challenges arose even within a wellintegrated health care delivery system highlights the difficulty of implementing new interventions to address adherence.

It is possible that by only enrolling patients who could identify a CVS pharmacy to which the medication should be sent, we identified a sample that was already more likely to pick up medications. In addition, since patients were already receiving interventions directly from the CVS pharmacy prior to this intervention, the potential for incremental improvement may have been limited. The Geisinger system has a distinctive structure, including universal use of e-prescribing, so the findings here may not be generalizable to other settings.

\section{Conclusions}

This adherence intervention trial had 2 key findings. First, the observed rate of PMN was much lower than previously reported from this same health care system just a few years ago. Further studies in this and other settings are needed to determine if the prior research identifying PMN has actually led to positive changes over time or whether the low PMN observed is a result of the selection criteria used for this study. Second, the lack of effect of the intervention shows that PMN among those patients who have not picked up a new prescription may be difficult to change, perhaps requiring interventions that move beyond telephone outreach to reconnect patients with their primary care providers who prescribed the medication.

\section{Authors}

MICHAEL A. FISCHER, MD, MS, is Associate Professor of Medicine, and JING XIE, MD, ScD, was Research Specialist at the time of this study, Division of Pharmacoepidemiology and Pharmacoeconomics, Brigham and Women's Hospital, Boston, Massachusetts. ERIC WRIGHT, PharmD, BCPS, is Investigator, Geisinger Center for Health Research, Danville, Pennsylvania, and Associate Professor, Department of Pharmacy Practice, Wilkes University, Wilkes-Barre, Pennsylvania; J.B. JONES, PhD, MBA, is Senior Investigator, Sutter Health, Sacramento, California; and RYAN P. VAN LOAN, is Project Coordinator, Geisinger Health Systems, Danville, Pennsylvania. LAUREN GALLAGHER, MPH, is Analytics Advisor, and WILLIAM H. SHRANK, MD, MSHS, is Senior Vice President, Chief Scientific Officer, and Chief Medical Officer of Provider Innovation, CVS Health, Woonsocket, Rhode Island. AARON M. WURST, is MBA Candidate, Harvard Business School, and Manager of Strategic Product Development, CVS Health, Woonsocket, Rhode Island.

AUTHOR CORRESPONDENCE: Michael A. Fischer, MD, MS, Division of Pharmacoepidemiology and Pharmacoeconomics, Brigham and Women's Hospital, 1620 Tremont St., Ste. 3030, Boston, MA 02120. Tel.: 617.278.0930; Fax: 617.232.8602;

E-mail:mfischer@partners.org.

\section{DISCLOSURES}

This research was supported by a grant from the National Association of Chain Drug Stores Foundation. Fischer and Shrank have received research support from CVS-Caremark. Fischer served on the CVS-Caremark Digital Health Advisory Board. Since completion of the research study, Shrank has become an employee of CVS-Caremark. Gallagher is an employee of CVSCaremark, and Wurst was an employee of CVS-Caremark at the time of the study. Jones, Wright, Van Loan, and Xie have no conflicts of interest to report.

Study concept and design were primarily contributed by Fischer and Shrank, assisted by the rest of the authors. Jones, Wright, Van Loan, Gallagher, and Wurst collected the data, which were interpreted by all authors equally. The manuscript was written by Fisher, Shrank, Xie, James, Wright and Van Loan, with assistance from Gallagher and Wurst. All authors worked equally on the revision.

\section{ACKNOWLEDGMENTS}

We gratefully acknowledge Joyce Lii for assistance with statistical programming

\section{REFERENCES}

1. New England Healthcare Institute. Thinking outside the pillbox: a system-wide approach to improving patient medication adherence for chronic disease. NEHI Research Brief. August 2009. Available at: http://www. nehi.net/writable/publication_files/file/pa_issue_brief_final.pdf. Accessed December 20, 2014.

2. IMS Institute for Healthcare Informatics. Avoidable costs in U.S. healthcare: the $\$ 200$ billion opportunity from using medicines more responsibly. 2013. Available at: http://www.imshealth.com/deployedfiles/imshealth/ Global/Content/Corporate/IMS\%20Institute/RUOM-2013/IHII_Responsible_ Use_Medicines_2013.pdf. Accessed December 20, 2014.

3. Osterberg L, Blaschke T. Adherence to medication. N Engl J Med. 2005;353(5):487-97.

4. Benner J, Glynn R, Mogun H, Neumann P, Weinstein M, Avorn J. Longterm persistence in use of statin therapy in elderly patients. JAMA. 2002; 288(4):455-61

5. Choudhry NK, Setoguchi S, Levin R, Winkelmayer WC, Shrank WH. Trends in adherence to secondary prevention medications in elderly post-myocardial infarction patients. Pharmacoepidemiol Drug Saf. 2008;17(12):1189-96

6. Monane M, Bohn RL, Gurwitz JH, Glynn RJ, Levin R, Avorn J. Compliance with antihypertensive therapy among elderly Medicaid enrollees: the roles of age, gender, and race. Am J Public Health. 1996;86(12):1805-08.

7. Chan DC, Shrank WH, Cutler D, et al. Patient, physician, and payment predictors of statin adherence. Med Care. 2010;48(3):196-202

8. Choudhry NK, Fischer MA, Avorn J, et al. The implications of therapeutic complexity on adherence to cardiovascular medications. Arch Intern Med. 2011;171(9):814-22

9. Choudhry NK, Fischer MA, Avorn J, et al. At Pitney Bowes, value-based insurance design cut copayments and increased drug adherence. Health Aff (Millwood). 2010;29(11):1995-2001

10. Shrank WH, Gleason PP, Canning C, et al. Can improved prescription medication labeling influence adherence to chronic medications? An evaluation of the Target pharmacy label. J Gen Intern Med. 2009;24(5):570-78.

11. Shrank WH, Hoang T, Ettner SL, et al. The implications of choice: prescribing generic or preferred pharmaceuticals improves medication adherence for chronic conditions. Arch Intern Med. 2006;166(3):332-37.

12. Shrank WH, Liberman JN, Fischer MA, et al. Are caregivers adherent to their own medications? J Am Pharm Assoc (2003). 2011;51(4):492-98.

13. Cutrona SL, Choudhry NK, Stedman M, et al. Physician effectiveness in interventions to improve cardiovascular medication adherence: a systematic review. J Gen Intern Med. 2010;25(10):1090-96. 
14. Kripalani S, Yao X, Haynes RB. Interventions to enhance medication adherence in chronic medical conditions: a systematic review. Arch Intern Med. 2007;167(6):540-49.

15. Viswanathan M, Golin CE, Jones CD, et al. Interventions to improve adherence to self-administered medications for chronic diseases in the United States: a systematic review. Ann Intern Med. 2012;157(11):785-95.

16. Fischer MA, Stedman M, Lii J, et al. Primary medication non-adherence: analysis of 195,930 electronic prescriptions. J Gen Internl Med. 2010;25(4):284-90.

17. Fischer MA, Choudhry NK, Brill G, et al. Trouble getting started: predictors of primary medication nonadherence. Am J Med. 2011;124(11):1081.

18. Shrank WH, Choudhry NK, Fischer MA, et al. The epidemiology of prescriptions abandoned at the pharmacy. Ann Intern Med. 2010;153(10):633-40.

19. Derose SF, Green K, Marrett E, et al. Automated outreach to increase primary adherence to cholesterol-lowering medications. JAMA Intern Med. 2013;173(1):38-43.
20. Shah NR, Hirsch AG, Zacker C, Taylor S, Wood GC, Stewart W. Factors associated with first-fill adherence rates for diabetic medications: a cohort study. J Gen Intern Med. 2009;24(2):233-37.

21. Shah NR, Hirsch AG, Zacker C, et al. Predictors of first-fill adherence for patients with hypertension. Am J Hypertens. 2009;22(4):392-96.

22. Karter AJ, Parker MM, Moffet HH, Ahmed AT, Schmittdiel JA, Selby JV. New prescription medication gaps: a comprehensive measure of adherence to new prescriptions. Health Serv Res. 2009;44(5 Pt 1):1640-61.

23. Raebel MA, Carroll NM, Ellis JL, Schroeder EB, Bayliss EA. Importance of including early nonadherence in estimations of medication adherence. Ann Pharmacother. 2011;45(9):1053-60.

24. Raebel MA, Ellis JL, Carroll NM, et al. Characteristics of patients with primary non-adherence to medications for hypertension, diabetes, and lipid disorders. J Gen Intern Med. 2012;27(1):57-64.

25. Pharmacy Quality Alliance. PQA performance measures. Primary medication non-adherence (PMN). Available at: http://pqaalliance.org/images/ uploads/files/PQA\%20measuresJuly2014.pdf. Accessed January 7, 2015. 
APPENDIX A Patients Erroneously Identified for Study Who Had Prior Use of Index Medications or Subclass Within 13 Months Before the Index Prescription

\begin{tabular}{|c|c|c|c|c|}
\hline Group & $\begin{array}{l}\text { Patients with the Same } \\
\text { Medication on File (n) }\end{array}$ & $\%$ & $\begin{array}{l}\text { Patients with the Same } \\
\text { Therapeutic Subclass (n) }\end{array}$ & $\%$ \\
\hline Adherent $(n=4,532)$ & 99 & 2.2 & 122 & 2.7 \\
\hline Nonadherent, control $(n=148)$ & 9 & 6.1 & 12 & 8.1 \\
\hline Nonadherent, intervention $(n=142)$ & 10 & 7.0 & 13 & 9.2 \\
\hline
\end{tabular}

\begin{tabular}{l|c|c|c}
\hline APPENDIX B & \multicolumn{3}{l}{$\begin{array}{l}\text { Primary Outcome Rate } \\
\text { Excluding 19 Patients with } \\
\text { Prior Use of Same Medication }\end{array}$} \\
\hline Group & Filled & Total & $\%$ \\
\hline Nonadherent, control & 33 & 139 & 23.7 \\
\hline Nonadherent, intervention & 34 & 132 & 25.8 \\
\hline
\end{tabular}

\section{APPENDIX D}

Multivariate-Adjusted Odds Ratios (95\% Cl) of Filling Rate Excluding 19 Patients with Prior Medication Name

\begin{tabular}{l|c|c|c}
\hline Variables & Odds Ratio & $95 \%$ CI & $P$ Value \\
\hline Intervention vs. control & 1.07 & $0.60-1.90$ & 0.82 \\
\hline Age & 1.02 & $1.00-1.04$ & 0.05 \\
\hline \multicolumn{4}{|l|}{ Index drug class } \\
\hline Asthma (reference) & 1.00 & & \\
\hline Diabetes & 0.99 & $0.33-3.01$ & 0.99 \\
\hline Hypertension & 1.72 & $0.88-3.36$ & 0.11 \\
\hline Lipids & 0.78 & $0.29-2.11$ & 0.62 \\
\hline Charlson score & 0.87 & $0.64-1.17$ & 0.35 \\
\hline Commercial insurance & 1.09 & $0.56-2.11$ & 0.80 \\
\hline CI=confidence interval. & & \\
\hline
\end{tabular}

\section{APPENDIX C Primary Outcome Rate Excluding} 25 Patients with Prior Use of Same Medication Subclass

\begin{tabular}{l|c|c|c}
\hline Group & Filled & Total & $\%$ \\
\hline Nonadherent, control & 31 & 136 & 22.8 \\
\hline Nonadherent, intervention & 32 & 129 & 24.8 \\
\hline
\end{tabular}

\section{APPENDIX E Multivariate-Adjusted Odds Ratios (95\% Cl) of Filling Rate Excluding 25 Patients with Prior Medication Subclass}

\begin{tabular}{|c|c|c|c|}
\hline APPENDIX E & \multicolumn{3}{|c|}{$\begin{array}{l}\text { Multivariate-Adjusted Odds } \\
\text { Ratios (95\% Cl) of Filling Rate } \\
\text { Excluding } 25 \text { Patients with } \\
\text { Prior Medication Subclass }\end{array}$} \\
\hline Variables & Odds Ratio & $95 \% \mathrm{CI}$ & $P$ Value \\
\hline Intervention vs. control & 1.04 & $0.58-1.88$ & 0.90 \\
\hline Age & 1.02 & $1.00-1.04$ & 0.04 \\
\hline \multicolumn{4}{|l|}{ Index drug class } \\
\hline Asthma (reference) & 1.00 & & \\
\hline Diabetes & 1.08 & $0.35-3.30$ & 0.89 \\
\hline Hypertension & 1.81 & $0.91-3.60$ & 0.09 \\
\hline Lipids & 0.84 & $0.31-2.29$ & 0.73 \\
\hline Charlson score & 0.87 & $0.64-1.17$ & 0.35 \\
\hline Commercial insurance & 1.13 & $0.57-2.23$ & 0.73 \\
\hline
\end{tabular}

